\title{
The Story Theory is a Key Element of Many Holistic Nursing Procedures
}

Andrzej Brodziak $^{1,2 *}$, Agnieszka Wolinska ${ }^{2}$ and Alicja Rozyk-Myrta ${ }^{2}$

${ }^{1}$ Institute of Occupational Medicine and Environmental Health, Sosnowiec, Poland

${ }^{2}$ Institute of Nursing, University of Applied Sciences, Nysa, Poland

${ }^{*}$ Corresponding author: Andrzej Brodziak, Institute of Occupational Medicine and Environmental Health, Sosnowiec, Poland, Tel: +48322660885; Fax: +48322661124; E-mail: andrzejbrodziak@wp.pl

Rec date: November 14, 2017; Acc date: November 27, 2017; Pub date: November 30, 2017

Copyright: ( 2017 Brodziak A, et al. This is an open-access article distributed under the terms of the Creative Commons Attribution License, which permits unrestricted use, distribution, and reproduction in any medium, provided the original author and source are credited.

\begin{abstract}
The authors draw attention to the effective procedure performed by nurses aimed to counteract the adverse consequences of loneliness, the essence of which is due to the so-called "Story Theory". They recall that this "Story Theory" is one of the so-called "Middle Range Theories for Nursing", proposed by Mary Jane Smith and Patrycja Lier, which is a useful tool in formulating various psychotherapeutic interventions. The authors cite two of their own previous works, related to so-called "life review therapy," in which they also proposed practical therapeutic procedures in line with the essence of the "Story Theory". The cited papers describe the rules of conversation, enabling patients to obtain a "balanced, memorized assessment of one's own live". The authors remark that the present proposal of the Story Theory coincides with the current and increasingly more explicit awareness in the field of sociology and political science of the importance of the so-called narrative, or just constructing new stories, supporting the promotion of new, social ideas.
\end{abstract}

Keywords: Story theory; Loneliness; Holistic nursing; Befriending; Cognitive behavioral therapy; Life review psychotherapy

\section{Introduction}

Recently, Rita Rubin published an interesting commentary entitled: Loneliness Might Be a Killer, but What's the best way to protect against it? [1]. She quotes arguments indicating that loneliness has a negative impact on health and increases the premature mortality. It occurred however, that the ways of counteracting these negative influences, devised in an intuitive way, such as befriending, do not attain the desired effects. Instead of sending volunteer befrienders to lonely people, an appropriate kind of talking with them is more efficient. It is the essence of the LISTEN (Loneliness Intervention using Story Theory to Enhance Nursing-sensitive outcomes) procedure proposed by Theeke et al. [2].

The team of nurses led by Theeke elaborated this procedure basing on the so-called "Story Theory" [3]. This theory, classified as a Middle Range Theory for Nursing, was proposed by Smith and Lier $[4,5]$.

\section{The Essence of the Story Theory and LISTEN Procedure}

The meaning of the "Story theory" is universal. Patricia Lier writes that: " The Story theory is composed of three interrelated concepts: (1) intentional dialogue, (2) connecting with self-in-relation, and (3) creating ease. According to the theory, the story is a narrative happening of connecting with self-in-relation through intentional dialogue to create ease. Ease emerges in the midst of accepting the whole story as one's own in a process of attentive embracing"[5].

The LISTEN procedure consists, in practice, on performing a 5session intervention that is delivered in a small group setting (3-5 people). Each of these sessions is similar to dialogues conducted in the course of cognitive behavioral therapy and aims to heal psychological misperceptions.
The content of these sessions is focused on particular important elements of the problem which should be overcome. Therefore, the first session is focused on perceived belonging as the notion important for the perception of loneliness. The second session focuses on relationships because it is important for the patients to identify more meaningful and less meaningful relationships. It guides participants towards enhanced awareness about past and current relationships. This session facilitates a thoughtful reflection of self in relation to others and the community.

The third session explores the patterns of getting out or staying in. Loneliness may be partly due to a physical handicap which hinders interpersonal relationships. During this session, the participants discuss how other lonely people get out of the house or cope with loneliness while stay in.

Session four helps to identify the realities of coping with loneliness based on one's own experience and the experience of others. Participants are encouraged to identify the positive, negative and turning points in their experience of loneliness.

The fifth session is about life lessons on loneliness, the experiences of loneliness and what might work to decrease loneliness. It encourages the participants to formulate the possible means to solve the problem. The degree of perception of loneliness and its changes can be assessed using the known UCLA Loneliness scale [6].

\section{Significance of the Story Theory for Counseling in Various Existential Problems}

As we mentioned, the "story theory" is a universal tool that is useful in overcoming various existential and health problems.

We already drew attention to this in our former work devoted to "life review psychotherapy" [7]. We proposed in that paper the practical procedure of enabling nurses to conduct "life review therapy". Life review is evoked by several recommendations envisaged by the 
Page 2 of 2

proposed procedure like: "Ask the patient for some statements about his life", "try to ask the patient about details of the story of his life", "determine the so-called sequence of unfavorable events" [7]. The proposed procedure is in accordance with Patricia Lier's "story theory". Our procedure also encompasses: (1) intentional dialogue, (2) trying to connect its content with self-in-relation, and (3) trying to create ease.

\section{Discussion}

In our earlier work, we also proposed very practical ways to enable therapists, especially nurses, to aid the patient to restructure his remembrances and create a more "uplifting" story of his life [8]. In other words, we formulate in this paper the rules to support patients in obtaining a "balanced, memorized assessment of one's own live." For this purpose, we first discuss data sets related to the course of personal life and then formulate the general guidelines how to assist the patient to reorganize his/her memories so that the remembered autobiography could have a positive connotation. We argue that the guidance provided to patients in this respect is, in fact the use of some type of cognitive behavioral therapy. Since the use of these methods is very time consuming, we propose a supplementary method of action by recommending so-called "therapeutic tasks". The life review interview, as a useful procedure for nurses, is also proposed by Ando et al. [9].

Reminiscences and narratives are elements of yet some other publications devoted to nursing practice [10-19].

Therefore, not only the works of Theeke et al. on ways to counteract the negative effects of loneliness, but also cited papers emphasize how important the "story theory" is for a holistic approach in medicine.

Moreover, this coincides with the current more and more explicit awareness in the field of sociology and political science of the importance of the so-called narrative, or just constructing new stories supporting the promotion of new, social ideas.

\section{Conclusion}

1. One of the so-called "Middle Range Theories for Nursing" called the "Story Theory" is a useful tool in formulating various psychotherapeutic interventions.

2. The effective procedure LISTEN (Loneliness Intervention using Story Theory to Enhance Nursing-sensitive outcomes) is an example of the applying the Story Theory in holistic nursing practice.

3. The proposed procedures for "life review therapy", supplemented by supporting tools in the form of "therapeutic tasks" are also an example of the usefulness of the Story Theory.

4. The present proposal of the "Story Theory" coincides with the current and increasingly more explicit awareness in the field of sociology and political science of the importance of the so-called narrative, or just constructing new stories, supporting the promotion of new, social ideas.

\section{References}

1. Rubin R (2017) Loneliness might be a killer, but what's the best way to protect against it? JAMA.

2. Theeke LA, Mallow JA, More J (2016) Effectiveness of LISTEN on loneliness, neuroimmunological stress response, psychosocial functioning, quality of life, and physical health measures of chronic illness. Int J Nurs Sci 3: 242-251.

3. Theeke LA, Mallow JA (2015) The Development of LISTEN: A novel intervention for loneliness. Open J Nurs 5: 136-143.

4. Smith MJ, Liehr P (2005) Story theory: Advancing nursing practice scholarship. Holist Nurs Pract 19: 272-6.

5. Lier P, Smith MJ (2014) Middle range theory for nursing. Springer Pub Co New York, USA.

6. Russell D, Peplau LA, Ferguson ML (1980) The revised UCLA loneliness scale: Concurrent and discriminant validity evidence. J Pers Soc Psychol 39: 472-480.

7. Brodziak A, Wolinska A, Ulman A, Gadek M, Rozyk-Myrta A (2017) Theoretical background and procedure for life review psychotherapy conducted by nurses in relation to older people. J Gerontol Geriatr Res 6: 403.

8. Brodziak A, Rózyk-Myrta A, Wolinska A (2016) How to arrange the remembrance of own life for the benefit of successful aging. J Gerontol Geriatr Res 5: 359 .

9. Ando M, Morita BT (2012) Factors related to spirituality for terminally ill cancer patients through Life review interview in Japan. J Palliative Care Med S1:002.

10. Gaydos HL (2005) Understanding personal narratives: An approach to practice. J Adv Nurs 49: 254-259.

11. Skott C (2001) Caring narratives and the strategy of presence: Narrative communication in nursing practice and research. Nurs Sci Q 14: 249-254.

12. Aloi JA (2009) The nurse and the use of narrative: An approach to caring. J Psychiatr Ment Health Nurs 16: 711-715.

13. Romanoff BD, Thompson BE (2006) Meaning construction in palliative care: The use of narrative, ritual, and the expressive arts. Am J Hosp Palliat Care 23: 309-16.

14. Wolf ZR (2008) Nurses' stories: Discovering essential nursing. Medsurg Nurs 17: 324-329.

15. Burnside I, Haight B (1992) Reminiscence and life review: Analysing each concept. J Adv Nurs 17: 855-862.

16. Haight B, Burnside I (1993) Reminiscence and life review: Explaining the differences. Arch Psychiatr Nurs 7: 91-98.

17. Burnside I, Haight B (1994) Reminiscence and life review: Therapeutic interventions for older people. Nurse Pract 19: 55-61.

18. Stinson KC (2009) Structured group reminiscence: An intervention for older adults. J Continuing Edu in Nurs 40: 521-528.

19. Thorgrimsdottir SH, Bjornsdottir K (2016) Reminiscence work with older people: The development of a historical reminiscence tool. Int J Older People Nurs 11: 70-79. 